\title{
Second International Workshop on Teaching and Learning of Information Retrieval (TLIR 2008)
}

London, UK

18 October 2008 


\section{Abstract}

Information Retrieval (IR) is a research area that has generated a great deal of interest in recent years, largely due to the growth of the Internet. Many different problems that have arisen during this time have been tackled by the efforts of thousand of researchers around the world. New advances are spread following the usual scientific channels, i.e. journals and conferences, keeping researchers abreast of new developments in the field.

Therefore as important as research is to IR, one way to improve the profile of the subject is to create a common space where IR lecturers and researchers can share their experiences and opinions in the field of IR teaching at any of the educational levels (primary, secondary and tertiary). The aim of the workshop was to provide this common space. 


\section{Full Synopsis}

Information Retrieval (IR) is a research area that has generated a great deal of interest in recent years, largely due to the growth of the Internet. Many different problems that have arisen during this time have been tackled by the efforts of thousand of researchers around the world. New advances are spread following the usual scientific channels, i.e. journals and conferences, keeping researchers abreast of new developments in the field.

However we need to ensure that students who study the subject of IR understand the basis of this discipline, not just with the aim of conducting research in the future for example, but also as a way of learning how search engines work - tools that they use for their own benefit on a daily basis. IR is a very useful subject to reinforce the knowledge acquired in other fields, such as programming, data structures, user interface design etc.

Postgraduate students who may conduct research in this area also need to know the fundamental aspects of the subject, simply because they may be building new solutions for them.

Therefore as important as research is to IR, one way to improve the profile of the subject is to create a common space where IR lecturers and researchers can share their experiences and opinions in the field of IR teaching at any of the educational levels (primary, secondary and tertiary). The aim of the workshop was to provide this common space.

The first edition of the workshop was held in January 10th, 2007, under the auspices of the BCS-IRSG at the BSC Headquarters in London. This second edition was designed to provide an event which will strengthened the community, attracting both young and experienced lecturers, and encourage them to present their experiences and ideas, in order to obtain valuable feedback from an audience with the same interests.

We have a number of broad topics to which we invited position papers on using the following categories:

\section{Level 1}

[A] Technical Level (Non-technical Mid-way to Technical continuum)

[B] Educational Goals

[b1] Library and information Science

[b2] Computer Science

[b3] MIS

[b4] Linguistics 


\section{Level 2}

[1] Teaching and Learning methods:

[1a] classroom;

[1b] elearning (distance learning);

[2] Assessment and feedback

[3] Curricula.

\section{Workshop Organisers}

Andrew MacFarlane (andym@soi.city.ac.uk),

City University London, Great Britain.

Juan F. Huete (ihg@decsai.ugr.es),

University of Granada, Spain.

Juan M. Fernandez-Luna (imfluna@decsai.ugr.es),

University of Granada, Spain.

Efthimis N. Efthimiadis (efthimis@u.washington.edu),

University of Washington, U.S.A. 


\section{Papers:}

Clare Thornley Teaching information retrieval (IR) as a philosophical problem http://dx.doi.org/10.14236/ewic/TLIR2008.1

Frances Johnson On the relation of search and engines http://dx.doi.org/10.14236/ewic/TLIR2008.2

Ian Ruthven, David Elsweiler and Emma Nicol Designing for users: an holistic approach to teaching Information Retrieval http://dx.doi.org/10.14236/ewic/TLIR2008.3

Fidel Cacheda, Diego Fernández, Rafael López Experiences on a Practical Course of Web Information Retrieval: Developing a Search Engine http://dx.doi.org/10.14236/ewic/TLIR2008.4 